Published in Dendrochronologia 20, 117-131, 2002

\title{
Climate modeling at various spatial and temporal scales: where can dendrochronology help?
}

\author{
Martin Beniston \\ Department of Geosciences \\ University of Fribourg \\ Switzerland
}

\begin{abstract}
This paper provides a brief overview of certain issues related to climate modeling and the role that dendrochronology can play, and has already played, in this context. Modeling is an essential approach to investigating the future evolution of the climate system in response to human activities. Tree-ring chronologies, on the other hand, have the capability of providing key parameters for model validation purposes, as well as baseline climates against which the possibly anomalous nature of current and future trends may be assessed.
\end{abstract}

The paper thus provides a succinct overview of climate models, their advantages and limitations, the manner by which dendrochronology can be used in model validation studies, and how models can be used to give insight into processes that explain the tree-ring chronologies. Recommendations for future research, based on the Third Assessment of the IPCC (Intergovernmental Panel on Climate Change) are included to highlight areas where dendrochronology may have added value in issues related to climate and environmental change.

\section{Introduction}

Over coming decades, humankind is likely to be subjected to the impacts of rapid environmental change that has been, at least in part, triggered as a result of human activities. While the balance between humans and their resource-base has always been delicate, the accelerated changes resulting from industrialization and significant global population increase over the last century has resulted in definite and sometimes irreversible damage and loss of resources. According to Myers and Tickel (2001), there have been more changes in the environment in the last 200 years than in the last 2,000, and more changes in the last 20 years than in the last 200. The rate of species extinction is now well beyond the natural rate, in what is sometimes referred to today as the "biotic holocaust". 
Global environmental change can be defined as a series of stress factors on the physical and biological systems of the planet. The Earth's environment has in the past been continuously subjected to various stresses through natural processes and, more recently, through human interference. Whether the global environment is capable of withstanding natural and anthropogenic stresses is a matter of constant debate. In some instances, the environment has, at least on local to regional scales, been able to revert to its previous levels. Examples of resilience include the acidity of lakes in Northern Ontario, Canada, which returned to their natural levels following significant abatement of sulfur-based pollution from major smelting plants (Gunn and Keller, 1990). In other instances, environmental damage appears to be irreversible; one example is the large perimeter of contaminated lands following the 1986 nuclear accident in Tchernobyl, Ukraine. Examples of irreversible degradation have provided arguments to those who believe that environmental impacts are cumulative and difficult to reverse.

The root causes of environmental mismanagement are to be found in economic policies and political options, and include:

- $\quad$ severe depletion of resources such as water and food availability in many parts of the world;

- loss of territory following sea-level rise, for example;

- changes in the sanitary situation of many populations, e.g., expansion of malaria as a result of climatic change;

- changes in extreme events; natural hazards related to extreme weather events are those that exert the greatest damage to the environment and infrastructure, and take the heaviest toll on life

The combined effects of climatic change, pollution, deforestation, desertification, soil degradation, and other features of global environmental change could lead up to more than 150 million refugees by the end of the $21^{\text {st }}$ century, according to international sources, including the Intergovernmental Panel on Climate Change (IPCC, 2001).

In view of these crucial issues, there is the need for numerical model approaches that allow a prediction of the evolution of the Earth system and its various interacting components, namely the atmosphere, the oceans, the cryosphere, and the biosphere. In any modeling enterprise, there is the requirement for data to provide model simulations with appropriate initial and boundary conditions, as well as for verifying the model's performance in simulating a particular process or set of processes.

This paper will address some of the issues related to modeling of environmental and climatic change, and the manner in which dendrochronology can be an essential component in providing baseline climate data. Such data can be used to assess the extent to which anthropogenic interference with the system may be 
leading to a rate and amplitude of change that is significantly different from changes in the past, when human-induced stress was minimal. 


\section{Issues to be considered with respect to studying climatic change}

Models are mathematical, computer-based, or conceptual tools that allow the synthesis of current understanding of particular systems in the realms of physics, chemistry, biology, or economics. In climate research, for example, atmospheric models attempt to take into account numerous elements of the system that are important for its evolution, in particular the oceans, the cryosphere, and the biosphere. Advanced models enable investigations of certain mechanisms that may ultimately be relevant to a system's evolution, such as feedbacks between its different constitutive elements, and the sensitivity of climate to disturbance. Models also have some measure of predictability for complex non-linear processes, which are the rule in the physical, biological or economic sciences.

The impacts of climatic change on the natural environment include the sensitivity of a given system to shifts in its environment, the vulnerability of that system to change, and its capacity for adaptation. Sensitivity of a system is an issue that requires adequate knowledge of its current conditions for sustainability, and the range of stresses that it can withstand without significant damage. Vulnerability of a system is the extent to which it may be damaged by changing environmental stresses; this may include not only the magnitude but also the rate of change. Adaptability refers to the degree to which ecological and socio-economic systems may adjust to changes in their environment; in many cases, natural and social systems have the capability to resist the adverse consequences of change or to benefit from new opportunities which environmental change may provide.

Policymakers need to pay close attention to the interpretation and implementation of specific legislation dealing with aspects of environmental change. In its Article 2, the UN Framework Convention on Climate Change (FCCC) stipulates that stabilization of atmospheric greenhouse gas concentrations should remain below a threshold "that would prevent dangerous anthropogenic interference with the climate system. Such a level should be achieved within a time-frame sufficient to allow ecosystems to adapt naturally to climate change, to ensure that food production is not threatened and to enable economic development to proceed in a sustainable manner". The challenges presented by Article 2 to the policymaker include the levels of greenhouse gases that can be regarded as dangerous, and what constitutes natural adaptability of ecosystems. Some will be very sensitive to small shifts in climatic conditions while others may hardly respond to large changes.

When analyzing the potential effects of climatic change on natural and socio-economic systems, it should be borne in mind that climate is in many instances only one of a range of stresses. For example, the IPCC (2001) has emphasized in its Third Assessment Report that human-induced climatic change represents an additional stress on systems that are already threatened by other changes. These include diminishing biodiversity, overexploitation of natural resources, air, water and soil pollution, as well as ozone depletion 
in the stratosphere. Because of this complex inter-linkage of stresses, it is exceedingly difficult to attribute impacts on natural or economic systems to any one particular element of environmental change such as climatic change, for example. As a result, the development of adaptation or mitigation strategies in the face of the uncertainties involved is by no means trivial.

\section{Climate models: a brief overview}

There are numerous approaches to simulating climate or components of the climate system. Models can be 1, 2, or 3-dimensional, and be applied to a single physical feature of relevance to climate, or may contain fully interactive, three-dimensional processes. In order to gain insight into the functioning of climate, the most complex models are not necessarily the most explicit; the type of model to be selected is therefore closely linked to the nature of the problem to be investigated (Henderson-Sellers and McGuffie, 1987; Beniston, 1997). There are three broad types of climate models, namely the quasi one-dimensional Energy Balance Models (EBM), the two-dimensional zonally-averaged Statistical-Dynamical Models (SDM), and the fully three-dimensional General Circulation Models (GCM); this latter type of model will be briefly discussed below.

\subsection{General Circulation Models}

General Circulation Models (GCMs) are essentially weather-forecasting models which operate at lower spatial resolution in order to integrate the governing equations much further ahead in time (years to decades as opposed to days for forecast models). They attempt to incorporate as many elements of the climate system as possible, and include not only the atmosphere, but also the oceans, the cryosphere, and the biosphere. GCMs are among the largest and most demanding applications in terms of computing resources. They typically solve large sets of equations on several million grid-points distributed in three dimensions around the globe, and these computations must be repeated 50 or more times per simulated day in order to adequately represent the temporal evolution of the system. Computer time and space requirements are thus extremely large, and GCM simulations require the use of the most advanced supercomputers. In order to undertake climate simulations within a reasonable time-frame, much of the physics representing feedbacks within the system needs to be parameterized, i.e., simplified in a physically-coherent manner. Despite the impressive computational resources used for climate modeling, and the progress in modeling techniques, many uncertainties and problems remain, in particular spatial resolution often inappropriate to provide information on the regional scale.

General circulation models are based on the physical dynamic and thermodynamic laws governing the atmosphere. These describe the redistribution of heat, momentum, and moisture resulting from atmospheric motion, radiative transfer and thermodynamics associated with phase changes of water. The governing 
equations are non-linear partial differential equations that require numerical methods for their solution. These consist in subdividing the atmosphere vertically into discrete layers, and horizontally either into discrete grid-points or by a finite number of mathematical functions as in so-called "spectral models". The values of the predicted variables, such as surface pressure, wind, temperature, humidity, and rainfall are integrated at each grid point (or for each spectral function) with respect to time, in order to obtain a prediction of the future state of these variables.

Parameterization, or the simplification of the equations through physically-coherent approximations, is implemented in numerical models for a number of reasons. Certain physical processes may be acting at a scale smaller than the characteristic grid interval, as in the case of turbulence, but which nevertheless have relevance to the evolution of the system. Other processes important for the functioning of the climate system, such as the physics associated with cloud formation and precipitation would, if computed explicitly at each time step and at every grid-point, overload the available computer resources. Parametric schemes thus need to be devised in order to take into account subgrid-scale features and complex physical processes in a physically-coherent and computationally-efficient manner. A parametric scheme attempts to relate the variables at unresolved scales to those resolved at model grid-points; the quality of GCM results are directly related to the quality of the parameterized physics.

\subsection{Coupled model systems}

Modelers have recognized the need to incorporate whenever possible as many elements of the climate system within a single numerical framework, though in practice this is exceedingly difficult due to the computational resources involved and the often limited understanding of numerous underlying feedback mechanisms. In addition, an integrated model seeks to simulate processes acting on vastly varying time scales, as illustrated in Figure 1. According to the component considered, the response time to a particular forcing can vary from a few hours to several centuries.

\section{Insert Figure 1 here}

In view of the significant influence of the oceans in terms of heat storage and the absorption of greenhouse gases, long-term simulations of climate requires a full three-dimensional ocean model. For example, if only sea-surface temperatures are prescribed for the ocean component of a climate model, climate predictability in the long term becomes questionable because features such as the quasi-periodic El-Niño/Southern Oscillation (ENSO), which exert major controls on the climate system, are not taken into account. Other features such as the formation of deep water also need to be simulated in a physically-coherent manner. Changes in the intensity and location of deep water formation can have profound effects on the atmosphere, and changes in the thermohaline circulation of the oceans have resulted in major climatic responses in the 
past, such as the cold « Younger-Dryas » period which affected Europe and other regions of the world after the end of the last glaciation (Broecker et al., 1985; Street-Perrott and Perrott, 1990; Salinger et al., 1989).

Recent developments in ocean system models that take into account not only surface processes at the oceanatmosphere interface, but also those acting at depth (i.e., deep ocean circulations related to the global ocean thermohaline circulation) have resulted in considerable improvements in the quality of climate model results. An oceanic GCM requires high spatial resolution to capture eddy processes that are key features of ocean dynamic exchange, and also bottom topography and basin geometry. High-resolution ocean models are therefore at least as costly in computer time as are atmospheric GCMs.

Coupled ocean-atmosphere in the 1990s systems represented the first attempt at integrated climate modeling. Today, further integration of other climate system component models include in particular the cryosphere and the biosphere, that are now being developed and applied to obtain more realistic simulations of climate on annual to century time scales.

\subsection{Regional Climate Models (RCMs)}

Regional-scale climate information is important for climate impacts research and policy making, where the resolution of climate information must be at scales much finer than those at which GCMs normally operate. Furthermore, processes acting on local or regional scales often feed into the climate system, so that investigations of scale-interactions as illustrated in Figure 1 are crucial to furthering our understanding of the climate system and the role of the smaller scales in its spatial and temporal evolution.

Small-scale features in non-linear systems are frequently responsible for apparently chaotic effects in the temporal evolution of those systems. In some instances, a long time may elapse before responses to a particular small-scale forcing become evident; when they do, however, the system may enter a totally new state. Pioneering work by Lorenz (1963) allowed to determine the implications of chaos theory in the atmospheric sciences. Lorenz developed a nominally simple model of the climate system in which only three modes, each associated with a particular wavelength, were considered. The model suggests that one of the basic properties of chaotic dynamics is the sensitive dependency of model solutions to initial conditions. Minor changes in initial conditions can result in very different solutions to the evolution of the atmospheric state after some time, as shown by Lorenz (1963) and for other types of non-linear systems by Nicolis and Prigogine, (1989).

One technique that is increasingly used to overcome problems related to the spatial resolution of GCMs is that of «nested modeling ». Results from a GCM for a particular region are used as initial and boundary conditions for a regional climate model (RCM) that operates at much higher resolution and, in most 
instances, with more detailed physical parameterizations. An RCM can theoretically be used to enhance the detail of regional climatology that would mostly be taking place at the sub-grid scale of a GCM. A regional model is in this case an « intelligent interpolator », since it is based on the physical mechanisms governing climatic processes. Such a procedure becomes particularly attractive for remote regions or those with topographic elements, whose complexity is unresolved by the coarse structure of a GCM grid, and where observational data is often sparse or nonexistent.

In its Third Assessment Report, the IPCC (2001) has extensively used the nested modeling technique in an attempt to improve regional climate information. The method, pioneered by Giorgi and co-workers (Giorgi and Mearns, 1991), has been reported in a number of case studies by different climate modeling groups worldwide. When driven by analyses and observations, RCMs generally simulate a realistic structure and evolution of synoptic events. Model biases with respect to observations are in the range of a few tenths to a few degrees for temperature and 10 - 40\% for precipitation. These biases tend to decrease with increasing resolution or decreasing RCM domain size. GCM-driven RCMs tend to produce less convincing results, however, which is to be expected since GCMs can generate unreliable results in terms of storm tracks and precipitation belts, for example. As a result, the errors of a GCM will tend to propagate into an RCM. RCMs may in some instances provide more realistic information on climatological processes than GCMs, however, because they capture the regional detail of key elements such as topography or large lakes in a far more realistic manner than GCMs. In the example illustrated in Figure 2, results for precipitation and temperature have been compiled by Giorgi et al. (1994) for an RCM operating at $50 \mathrm{~km}$ resolution nested into a GCM with a $300 \mathrm{~km}$ resolution.

Insert Figure 2 here

The salient differences observed in this illustration are directly related to the enhanced RCM resolution and to the improved regional detail. In this example, predictions of precipitation changes in Europe show a decrease in a warmer climate according to the GCM simulations and, conversely, an increase in the RCM. This can be explained by the fact that the GCM grid poorly resolves European mountain ranges such as the Alps, the Pyrenees, or the Carpathians, while the RCM is capable of better representing the mountains and thus the enhancement of precipitation which they generate. In other regions, discrepancies between the two climate models are not so important, in part because the orographic effect is either not the dominant factor for precipitation, or because the mountain ranges involved are sufficiently extensive to be adequately resolved in the GCM.

\subsection{Model validation}

Abstract theories and models need to be validated, in order to have some degree of confidence in their projections and analyses. In many cases, the limits of our understanding reduce the predictive ability of the 
modeling systems involved, so that the purpose of validation is not so much to prove the absolute accuracy of a model as to define the degree of uncertainty of its results and the limits of applicability. By comparing model results with measurements and observations as far as possible, improvements in model design or recommendations for developing new parameterizations can be suggested.

Theories and models are normally designed to address classes of similar issues. Before they can be used to answer specific questions, they must be adapted to the particular conditions of the problem to be analyzed. This is achieved through the specification of initial and boundary conditions. Model initialization occurs when the state of the system is specified at the beginning of the computation, by setting each of the dependent variables to some reference value obtained from observation or hypothesis. In a GCM, for example, model initialization is not trivial, because the information used to initialize a simulation must not only be processed in a manner suited to the internal structure of a model, but it must also be consistent with the laws and relations which define the model.

Boundary conditions are also a necessary part of any model simulation. These describe constraints on the evolution of the system, or interactions between the system and its environment that are not described explicitly by the model. In a GCM, the lower boundary condition defines the topographic, dynamic, thermal and moisture characteristics of the Earth's surface; the upper boundary condition is generally set at the "top of the atmosphere”, where incoming solar radiation is the main forcing factor for the climate system. In an RCM, on the other hand, additional conditions in the form of lateral boundary conditions are necessary to describe the constraints associated with limited-area models.

\subsection{Range of application of climate models}

Confidence in modeling techniques may be reduced for a number of reasons related to the technique itself, a limited understanding of the biogeophysical mechanisms governing a particular system, or inadequate data for validation purposes.

Models suffer from insufficient spatial resolution and an incomplete description of feedback mechanisms and interactions between various elements of the climate system. Initialization procedures are dependent on a set of physical, biological, economic, and demographic information that contain a wide range of uncertainties to which a model will be sensitive. Computational resources and mathematical algorithms, while in constant development and progress, have difficulty in adequately modeling some of the most complex systems in existence.

Despite these often constraining caveats, however, models have generally reached an advanced level of development. The results of these models, if viewed with sufficient caution, can be used to analyze the 
functioning and evolution of a number of environmental systems. For example, most climate models are today capable of providing an accurate representation of the broad characteristics of current climate, both in terms of average climatic conditions, as well as seasonal to interannual variability. Such observations increase confidence in model studies of future climatic change based upon a number of socio-economic scenarios, and encourage the commitment of the scientific community to future model development.

\section{Synergies between dendrochronology and climate models}

Models are central to our concepts of environmental physics, biological and ecosystem research, and socioeconomic issues; they cannot be dissociated from observational data, however. It is often erroneously believed that there is a cleavage between modeling approaches and experimentation or observation. Indeed, much of the scientific community today is split into two distinct groups, those working with data and those working with models with, in many cases, regrettably little interaction between the two communities. There is, however, no intrinsic reason to separate the two: data and models are by necessity complementary (Beniston, 2000).

Climatic variability is an important exogenous factor affecting numerous systems, from oceans and hydrology, to ecosystems and forest dynamics (Davis, 1986; Prentice, 1986). Both modeling and paleoecological approaches have proven useful in elucidating the effects of climate change on vegetation regeneration and succession. Current capability to predict climate-induced vegetation change is limited, however, by spatial and temporal scale problems (Neilson, 1986), and inadequate understanding of the

effects of climate variation on disturbance regimes (Graham et al., 1990; Overpeck et al., 1990). Separating climate-induced from human-caused vegetation changes represents a major challenge to properly assess the influence of climatic variations on vegetation dynamics.

The interrelated systems of climate, vegetation, and physical landscape are highly dynamic on time scales ranging from hours to millenia. The control of vegetation patterns by climate is most obvious at coarse spatial and temporal scales (Webb, 1987), but at time scales of decades to several centuries, the effects of climatic variation on vegetation dynamics have been less obvious. This is often due to the difficulty of separating disturbance-induced successional changes from climate-induced changes (Archer et al., 1995; Brubaker, 1986; Davis, 1986; Prentice, 1992; Veblen and Markgraf, 1988). However, it is precisely at time scales of years to decades that the understanding of the effects of climatic variation on vegetation change is so vital (Melillo et al., 1996; Overpeck et al., 1990; Solomon, 1986).

In terms of observational data, dendrochronology is perhaps one approach that has provided extremely valuable information related to environmental and climatic change. Tree-ring analyses have proven to be 
essential in climate and vegetation reconstruction over several centuries to millenia in many parts of the world, providing data for periods when direct instrumental observation is unavailable. Tree ring studies can also be used to determine fire histories and volcanic eruptions, stream-flow conditions using calibrated relationships between ring-width and runoff amounts, as well as certain forms of extreme climatic events.

Dendrochronological analysis is not without problems, however, because precipitation and temperature are not the sole determinants on tree growth. Furthermore, the biological response to climate forcing may change over time. Briffa et al. (1998) have shown that possibly as a result of warming in recent decades, the sensitivity of tree-ring density to temperature has changed. Carbon dioxide fertilization may also have an influence, particularly on tree species at high elevations.

Two distinct techniques provide climatic information, namely the measurement of annual ring width, and the analysis of wood density (Fritts, 1976; Schweingruber et al., 1979). Ring width, when corrected for age trend, varies strongly in response to summer temperature towards polar and upper altitude tree-lines, and to summer moisture near the lower altitude tree-line in arid regions (Tessier et al., 1997). In addition, the isotopic ratios (oxygen, deuterium and carbon) in tree-rings are the result of the response of the tree to complex biological and eco-physiological processes, of which climate is probably the dominant factor. As shown by Tessier et al. (1997), tree-ring chronologies need to be calibrated against absolutely-dated sequences (e.g., Schweingruber, 1993) and the signal-to-noise ratio has to be optimized. In this context, Hughes et al. (1982) have paved the way for methodologies that treat tree-ring sequences in such a way that climate-related information (i.e., the signal) is retained while non-climatic variation (i.e., the noise) is removed. In effect, the climatic factor is the only one that exhibits an annual periodicity and where the climatic anomalies are coherent over large regions. As a result, the inter-annual fluctuations of climate can be identified in the ring characteristics. Other issues such as the detection of, and distinction between, high, medium and low-frequency signals in the records need to be addressed when preparing a chronology (Tessier et al., 1997).

Once a chronology has been established, taking into account the problems inherent to its preparation, it can then be applied to the reconstruction of climatic conditions from the annual or even seasonal scales (e.g., Keller, 1999) to decadal and century time scales. Because of its high temporal resolution, dendrochronology has been extensively used for reconstructing climates of the past. Analyses from tree-ring chronologies allow to answer important questions related to whether the changes that models predict for the future have already taken place in the past. If such changes have occurred, when did they occur? In what part of the world were they present? What was the time-span of these changes, and the speed of onset or termination? Was human interference a component of the recorded environmental change? 
Dendrochronology has given scientists accurate baseline climate and environmental data for the last 2,0005,000 years according to the study region. Indeed, it is principally on the basis of dendrochronology that climate scientists have been able to show that the planet may well have entered a period of unprecedented warming, when compared to the last millenium. This is seen in Figure 3 (after Mann and Bradley, 1999; IPCC, 2001); the continuing trend into the $21^{\text {st }}$ century may bring the system rapidly into a state not experienced since the end of the last major ice age. Model predictions of climatic change over the next few decades enable a quantification of the anomalous nature of the amplitude and rate of change compared to the pre-industrial era.

Insert Figure 3 here

There have been a number of studies in recent years that have sought to reconstruct particular periods in a relatively distant past (several centuries) with particularly warm or cold seasonal and annual temperatures, based on width and density of annual growth rings (e.g., D’Arrigo et al., 1998; Hughes et al., 1999; Cook et al., 2000). Spatial reconstructions of past temperature variations and estimates of hemispheric and global temperature change (e.g., Briffa, 2000) have provided information on the functioning of climate in the absence of direct or significant human interference. ENSO (El Nino/Southern Oscillation) and the NAO (North Atlantic Oscillation) are known to exert major controls on global and regional climates on seasonal to decadal time-scales. Tree-ring networks are currently used to identify the behavior of ENSO and the NAO over the past several centuries (e.g., Stahle et al., 1998; Cook et al., 1998; Cullen et al., 2001). Climate models can benefit from the improved understanding of the causes of climatic variability associated with ENSO or the NAO. Coupled ocean-atmosphere models are currently improving their performance in their capability of reproducing these quasi-periodic forcings, in particular their onset and frequency of occurrence. Simulations of climates prior to the instrumental period rely on information provided by tree-ring chronologies for initialization and verification purposes.

Extremes, and not changes in means, generally have the strongest bearing on environmental disruption, damage, and loss of life. There is speculation (IPCC, 2001) that a warmer climate may be accompanied in many parts of the world by an increase in the frequency and severity of extremes. In some cases, this has been shown to be true (Frei and Schaer, 2000) for extreme precipitation in the Alps over the last 100 years, but the cause-to-effect relationship between observed $20^{\text {th }}$ century warming and a range of extremes is difficult to demonstrate. In some instances, shifts in extremes are related to forcing factors other than warming, as Beniston and Jungo (2001) have shown when relating the behavior of the North Atlantic Oscillation to that of temperature extremes in the Alps.

Insert Figure 4 here 
The statistics in Figure 4 show that in terms of loss of life, damage to infrastructure, environmental degradation, and economic losses, extreme climatic events such as wind storms and floods exceed those of earthquakes. The rising costs of damage claims has heightened the interests of the insurance industry and the research community alike in recent years. This has prompted interest in modeling studies to assess the possible changes in extremes in a changing climate, and to test the capability of models to reproduce past events such as strong wind storms (e.g., Goyette et al., 2001). Dendrochronological analyses can, on the other hand, provide information on the type of extreme event (i.e., hail, flood, drought, frost, wind damage, and fire), and the frequency of occurrence of such events that have occurred in the past; this provides the essential baseline information against which future changes can be compared.

Models are not only dependent on tree-ring data for initialization and verification purposes, but they can under certain circumstances be a powerful tool to explain the observed chronologies, particularly at the regional scale. For example, appropriate model initializations can help to simulate the atmospheric circulations, and the precipitation patterns embedded in these flows, that have resulted in particular configurations of tree-ring width and densities observed in a particular region for a given time frame. The model studies can thus provide insight as to whether the tree-rings have been influenced by local, regional, or large-scale shifts in precipitation or temperature. As previously mentioned, RCMs can also be used as "intelligent interpolators", in the sense that they can fill the gaps in sparse data and restitute missing climatic information for various geographic zones. This can be particularly of interest for remote highelevation or high-latitude sites.

At the large spatial scales, comparisons of records of past vegetation dynamics to paleoclimatic simulations by GCMs have improved the understanding of the role of climate in governing past vegetation change (Webb et al., 1993). Several major findings of paleo research have guided investigations of the effects of future climate change on the Earth's biota. These include changing seasonality, which may result in unexpected vegetation patterns (Prentice et al., 1991), rapid changes in both climate and vegetation with ecosystem-wide impilcations (Gear and Huntley, 1991), and short-term extreme events which may impact tree population structures (Lloyd and Graumlich, 1995).

Recent research involving both models and tree-ring data has focused on the simulation of future trends in tree-growth, on the basis of GCM model outputs (to establish future climate evolution) and calibrated treering to climate relationships (to assess the future response of tree growth to changing temperature and precipitation). Tessier et al. (1998) and Keller (1999) have used results from the French ARPEGE GCM to establish scenarios of climate change in southern France (from the Mediterranean into the southern French Alps) under conditions of doubled- $\mathrm{CO}_{2}$ concentrations in the atmosphere with respect to their pre-industrial values. Since the ARPEGE model has a variable grid, with high resolution over France (and a corresponding low resolution in the antipodes), the climatic scenario data is at a comparable resolution to 
that of an RCM. Warming is projected to be about $3^{\circ} \mathrm{C}$ on average, with a strong winter increase of about $5{ }^{\circ} \mathrm{C}$. Precipitation shows no definite trend other than during the Spring, during which the ARPEGE model suggests a relative increase in rainfall compared to current climate. Figure 5 illustrates the results of this study for a number of species common in this part of south-eastern France, namely Larix decidua and Pinus sylvestris. The figure shows the influence of climatic change on radial growth compared to the average growth observed during the 1901-1980 baseline period; the growth index simulated by tree-ring / climate relationships is also shown as a measure of the robustness of the method. In some instances, the trees respond to the changing climate, either by enhanced growth in mountain locations due to warmer conditions and a longer growing season or by reduced growth related to heat and drought stress in the summer in the coastal Mediterranean zone. In other instances (not shown in the figure), the trees show relatively little change in a doubled- $\mathrm{CO}_{2}$ climate, for a number of reasons reported by Tessier et al. (1998).

\section{Insert Figure 5 here}

This is but one example among many that richly illustrates the type of symbiosis that can - and should exist between observations and models in the realm of climate research. The complementarity of data and models is such that one approach can take over from the other to explain climate-related processes in particular regions and for particular times in the past, and on into the future. The dual modeling and dendrochronological approach allows to increase our confidence in the capability of using models outside of the range of current climatic conditions, i.e., for both the past and the future.

\section{Conclusions}

In terms of current and future climate investigations, research should continue to foster closer ties between the dendrochronological and climate modeling communities. Dendrochronology has already played a major role in the climate change debate, in the sense that it has provided much of the baseline climate information that has provided insight into climatic change over the past several centuries. The interpretation of tree ring chronologies has indeed been as important for past climate reconstructions as climate models have been for future climate evolution, in terms of shaping policy aimed at addressing climatic change (IPCC, 2001, for example). There is thus a wide range of issues where dendrochronology is likely to have "added-value" in the future, such as:

- Experimental studies: dendrochronology-based information has value for fundamental understanding of various processes relevant to climate, as well as for providing empirical data to numerical climate models. 
- Long-term monitoring, in remote regions and at high-elevations: tree-ring data could be useful to alleviate the sparsity of observational data and provide input to climate models.

- Specific regional field studies, including transects, would enable dendrochronology to establish a link with regional climate models, whose simulations often suffer from a lack of adequate information at the appropriate spatial scales for initialization and verification purposes.

- Dendrochronology per se: tree ring data is one of the most reliable climate archives for time scales of up to a few millenia; it can thus be used for the establishment of key environmental and climatic baselines. Such baselines are an essential part of the climate change debate, in the sense that they are a measure of natural climate variability against which the possibly anomalous nature of current and future trends can be assessed.

- Chronologies are also used for evaluating the response of ecosystems to natural climate variability. These allow climate-impacts specialists to assess the sensitivity and vulnerability of species to change, as a "first guess" at whether certain ecosystems will be sufficiently resilient to adapt to (or survive) expected climate change in coming decades. Such studies are essential to address issues on ecosystem security as defined by Article 2 of the UN Framework Convention on Climate Change.

- Links to numerical models: as already mentioned, tree-ring chronologies provide essential data for initialization and inter-comparison purposes with regional climate models. The trends reconstructed from tree-ring data can be used for testing other types of model as well, such as ecosystem response models, hydrological models, and cryosphere models.

Implementation of such research, which needs to be on the long time-scales characteristic of forest dynamics and processes associated with climatic change, will help further our understanding of the fundamental processes involved. This in turn will allow the formulation of appropriate adaptation or mitigation strategies that are likely to become increasingly necessary in many parts of the world as environmental changes begin to impact upon natural resources and, ultimately, socio-economic systems.

However, as noted by a number of specialists, climate reconstructions based entirely on tree-ring data are susceptible to various sources of contamination, in addition to non-linearity of response. The focus on paleo-climatic research has been for the past few years increasingly on "multi-proxy" estimates of past climatic and environmental change, i.e., supplementing tree-ring chronologies with other types of proxy data, such as varved sediments, ice-core data, etc. (e.g., Jones et al., 1998; Mann et al., 2000; Crowley and Lowery, 2000).

\section{References}

Archer, S., Schimel, D.S., and Holland, E.A., 1995: Mechanisms of shrubland expansion: land use, climate or $\mathrm{CO}_{2}$ ? Climatic Change 29:91-99

Beniston, M., 1997: From Turbulence to Climate. Springer, Heidelberg and New York, 330 pp. 
Beniston, M., 2000 : Environmental Change in Mountains and Uplands. Arnold Publishers, London, and Oxford University Press, New York, 172 pp.

Beniston, M., and Jungo, P., 2001: Shifts in the distributions of pressure, temperature and moisture in the alpine region in response to the behavior of the North Atlantic Oscillation. Theor. and Appl. Clim., in press

Briffa, K.R., 2000: Annual climate variability in the Holocene: interpreting the message of ancient trees. Quat. Sci. Rev., 19, 87-105

Broecker, W. S., Peteet, D., and Rind, D :, 1985 : Does the ocean-atmosphere system have more than one stable mode of operation ? Nature, 315, 21-26

Brubaker, L.B., 1986: Responses of tree populations to climate change. Vegetatio 67:119-130

Cook, E.R., B.M. Buckley and R.D. D’Arrigo, 2000: Warm-Season Temperatures since 1600 B.C. Reconstructed from Tasmanian Tree Rings and Their Relationship to Large-Scale Sea Surface Temperature Anomalies. Clim. Dyn., 16, 79-91

Cook, E.R., R.D. D’Arrigo and K.R. Briffa, 1998: A reconstruction of the North Atlantic Oscillation using tree-ring chronologies from North America and Europe. The Holocene, 8, 9-17

Crowley, T.J. and T. Lowery, 2000: How warm was the Medieval warm period? Ambio, 29, 51-54

Cullen, H., R. D’Arrigo, E. Cook and M.E. Mann, 2001: Multiproxy-based reconstructions of the North Atlantic Oscillation over the past three centuries. Paleoceanography, 16, 27-39

D’Arrigo, R.D., E.R. Cook, M.J. Salinger, J. Palmer, P.J. Krusic, B.M. Buckley and R. Villalba, 1998: Tree-ring records from New Zealand: long-term context for recent warming trend. Clim. Dyn., 14, 191199

Davis, M.B., 1986: Climatic instability, time lags, and community disequilibrium, Community Ecology, J. Diamond, and T.J. Case, (eds.), Harper and Row, New York, 269-284.

Frei, C., and Schaer, C., 2000 : Detection probability of trends in rare events: Theory and application to heavy precipitation in the Alpine region. Journal of Climate, 2001, 14, 1568-1584

Fritts, H.C., 1976: Tree Rings and Climate. Academic Press, New York.

Gear, A.J., and B. Huntley, 1991: Rapid changes in the range limits of Scots Pine 4,000 years ago, Science, 251, 544-547

Giorgi, F. and Mearns, L.O., 1991: Approaches to the simulation of regional climate change: a review. Reviews of Geophysics, 29: 191-216.

Giorgi, F., Brodeur, C.S., and Bates, G.T., 1994: Regional climate change scenarios over the United States produced with a nested regional climate model. J. Clim., 7, 375 - 399.

Goyette, S., Beniston, M., Jungo, P., Caya, D., and Laprise, R., 2001: Numerical investigation of an extreme storm with the Canadian Regional Climate Model: The case study of windstorm Vivian, Switzerland, February 27, 1990. Climate Dynamics, in press

Graham, R.L., Turner, M.G., and Dale, V.H., 1990: How increasing $\mathrm{CO}_{2}$ and climate change affect forests. BioScience 40:575-587

Gunn, J. M., and Keller, W., 1990: Biologial recovery of an acid lake after reduction in industrial emissions of sulphur. Nature, 345, 431-433

Henderson-Sellers, A., and K. McGuffie, 1987: A Climate Modeling Primer. J. Wiley, 217 pp.

Houghton, J., 1984 : The global climate. Cambridge University Press, Cambridge (UK), 233 pp.

Hughes, M. K., Kelly, P. M., Pilcher, J.R., and LaMarche, V.C., (eds), 1982: Climate from Tree Rings. Cambridge University Press, Cambridge, 223 pp.

Hughes, M.K., E.A. Vaganov, S. Shiyatov, R.Touchan and G. Funkhouser, 1999: Twentieth century summer warmth in northern Yakutia in a 600 year context. The Holocene, 9, 603-308

IPCC, 2001: Climate Change. The IPCC Third Assessment Report. Cambridge University Press, Cambridge and New York. Volumes I (The Scientific Basis), II (Impacts, Adaptation, and Vulnerability) and III (Mitigation)

Jones, P.D., K.R. Briffa, T.P., Barnett and S.F.B. Tett, 1998: High-resolution palaeoclimatic records for the last millennium: interpretation, integration and comparison with General Circulation Model control run temperatures. The Holocene, 8, 455-471

Keller, T., 1999 : Variabilité climatique interannuelle quantifiée à partir de la densité et des isotopes stables de la cellulose du bois. PhD Thesis, University of Aix-Marseille (France), 198 pp.

Lloyd, A.H., and L.J. Graumlich, 1995: Dendroclimatic, ecological, and geomorphological evidence for long-term climatic change in the Sierra Nevada, USA, Tree Rings, Environment, and Humanity, J.S. Dean, D.M. Meko, and T.W. Swetnam, (eds.), University of Arizona, Tucson, Arizona 
Lorenz, E. N., 1963: Deterministic non-periodic flow. J. Atmos. Sci., 20, 130 - 141

Mann, M., and Bradley, R. S., 1999: Northern Hemisphere temperatures during the past millennium: inferences, uncertainties, and limitations. Geophys. Res. Letters, 26, 759-762

Mann, M.E., E. Gille, R.S. Bradley, M.K. Hughes, J.T. Overpeck, F.T. Keimig and W. Gross, 2000: Global temperature patterns in past centuries: An interactive presentation. Earth Interactions, 4, 1-29

Melillo, J.M., Prentice, I.C., Farquhar, G.D., Schulze, E.-D., and Sala, O.E., 1996: Terrestrial biotic responses to environmental change and feedbacks to climate. In: Houghton, J.T., Meira Filho, L.G., Callander, B.A., Harris, N., Kattenberg, A., and Maskell, K., (eds), Climate Change 1995. The Science of Climate Change. Cambridge University Press, Cambridge, pp 447-481

Munich Re, 1999 : Annual review of natural catastrophes. Topics Journal, Munich.

Myers, N., and Tickell, C., 2001 : Cutting evolution down to our size. The Financial Times weekend supplement, October27-28, 2001

Neilson R. P., 1986: High-resolution climatic analysis and southwest biogeography. Science 232:27-34

Nicolis, G., and Prigogine, I., 1989: Exploring Complexity. Freeman Co., New York

Overpeck, J.T., Rind, D., and Goldberg, R., 1990: Climate-induced changes in forest disturbance and vegetation. Nature, 343, 51-53

Prentice, I.C., 1986: Vegetation response to past climate variation. Vegetatio 67:131-141

Prentice, I.C., 1992: Climate and long-term vegetation dynamics. In: Glenn-Lewin, D.C., Peet, R.A., and Veblen, T.T., eds: Plant Succession: Theory and Prediction. Chapman and Hall, London, pp 293- 339

Prentice, I.C., P.J. Bartlein, and T. Webb III, 1991: Vegetation and climate change in Eastern North America since the last glacial maximum, Ecology,72, 2038-2052

Salinger, M.J., J.M. Williams, and W.M. Williams, 1989: $\mathrm{CO}_{2}$ and Climate Change: Impacts on Agriculture, New Zealand Meteorological Service, Wellington.

Saltzmann, B., (Ed.), 1983, Theory of Climate. Advances in Geophysics, Vol. 25. Academic Press, New York, 505 pp.

Schweingruber, F. H., 1993: Jahrringe und Umwelt, Dendroökologie, WSL Publications, Birmensdorf, Switzerland, $474 \mathrm{pp}$.

Schweingruber, F.H., Bräker, O.U. and Schär, E., 1979: Dendroclimatic studies on conifers from central Europe and Great Britain. Boreas, 8: 427-52.

Solomon AM, 1986: Transient response of forests to $\mathrm{CO}_{2}$-induced climate change: simulation modeling experiments in eastern North America. Oecologia 68:567-579

Stahle, D.W., M.K. Cleaveland, M.D. Therrell, D.A. Gay, R.D. D’Arrigo, P.J. Krusic, E.R. Cook, R.J. Allan, J.E. Cole, R.B. Dunbar, M.D. Moore, M.A. Stokes, B.T. Burns, J. Villanueva-Diaz and L.G. Thompson, 1998: Experimental Dendroclimatic Reconstruction of the Southern Oscillation. Bull. Am. Met. Soc., 79, 2137-2152

Street-Perrott, F.A., and Perrott, R.A., 1990 : Lake levels and climate reconstructions. In : Hecht, A. (Ed.), Palaeo-Climate Analysis and Modeling. J. Wiley, New York, pp. 291-340

Tessier, L., Guibal, F., and Schweingruber, F. H., 1997: Research strategies in dendroecology and dendroclimatology in mountain environments. Climatic Change, 36, 267-285

Tessier, L., Guibal, F., and Schweingruber, F.H., 1997: Research strategies in dendroecology and dendroclimatology in mountain environments. Climatic Change, 36, 499 - 517

Tessier, L., Keller, T., Guiot, J., Edouard, J.-L., and Guibal, F., 1998: Predictive models of tree-growth: preliminary results in the French Alps. In: Beniston, M., and Innes, J. L. (eds.), The Impacts of Climate Variability on Forests, Springer-Verlag (Heidelberg and New York), pp. 109-120

Veblen, T.T., and Markgraf, V., 1988: Steppe expansion in Patagonia? Quatern Res 30:331-338

Webb, T., 1987: The appearance and disappearance of major vegetation assemblages long-term vegetational dynamics in eastern North America. Vegetatio 69:177-187

Webb, T., P.J. Bartlein, S.P. Harrison, and K.H. Anderson, 1993: Vegetation, lake levels and climate in eastern North America for the last 18,000 years, Global Climates Since the Last Glacial Maximum, H.E. Wright, J.E. Kutzbach, T. Webb III, W.F. Ruddiman, F.A. Street-Perrott, and P.J. Bartlein, (eds.), University of Minnesota Press, Minneapolis, 415-467 


\section{Figure captions}

Figure 1: Characteristic time scales of various components of the climate system (adapted from Saltzmann, 1983). The percentages indicate the relative amounts of energy entering the climate system.

Figure 2: Comparison of GCM and RCM results for precipitation changes $\left(2 \mathrm{x} \mathrm{CO}_{2}\right.$ climate minus current climate) in selected geographical regions for simulations in an enhanced greenhouse-gas climate.

Figure 3: Temperature reconstruction over the last millenium, adapted from Mann and Bradley (1999). Shaded area represents the limits of uncertainty; the bold line to the right is the instrumental temperature record for the $20^{\text {th }}$ century.

Figure 4: Statistics related to natural hazards, adapted from Munich Re (1999).

Figure 5: Simulated tree-ring growth for a 2 x $\mathrm{CO}_{2}$ climate scenario. Shown are the observed tree-ring index for the 1901-1980 baseline period, the simulated index using tree-ring/climate relationships, and the simulated response of tree growth to a changing climate. Adapted from Tessier et al. (1998).

Tree types. 1: Picea abies mountain location; 2: Larix decidua mountain location; 3: Larix decidua mountain location; 4: Larix decidua mountain location; 5: Pinus sylvestris coastal location. 
Figure 1

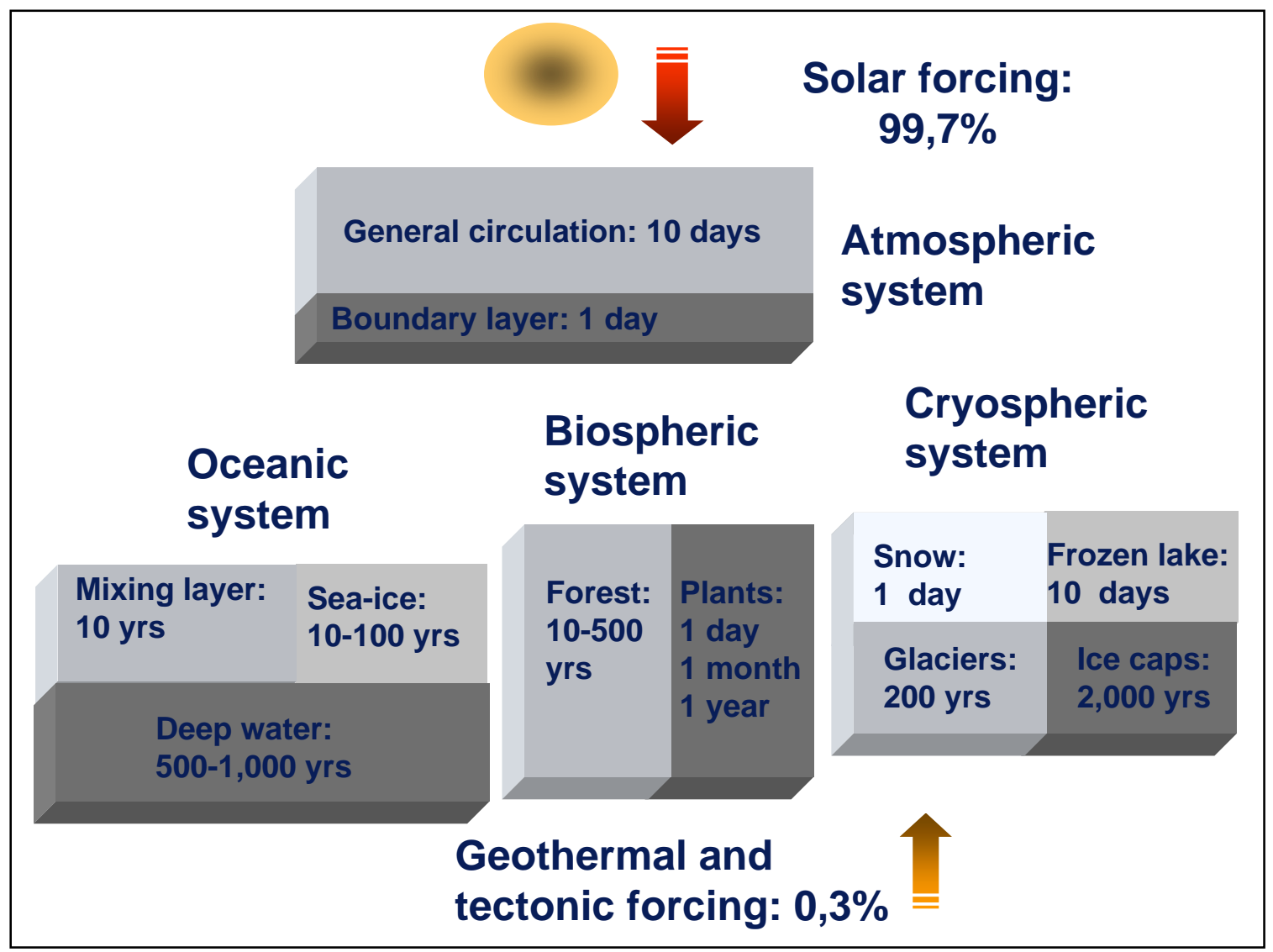


Figure 2

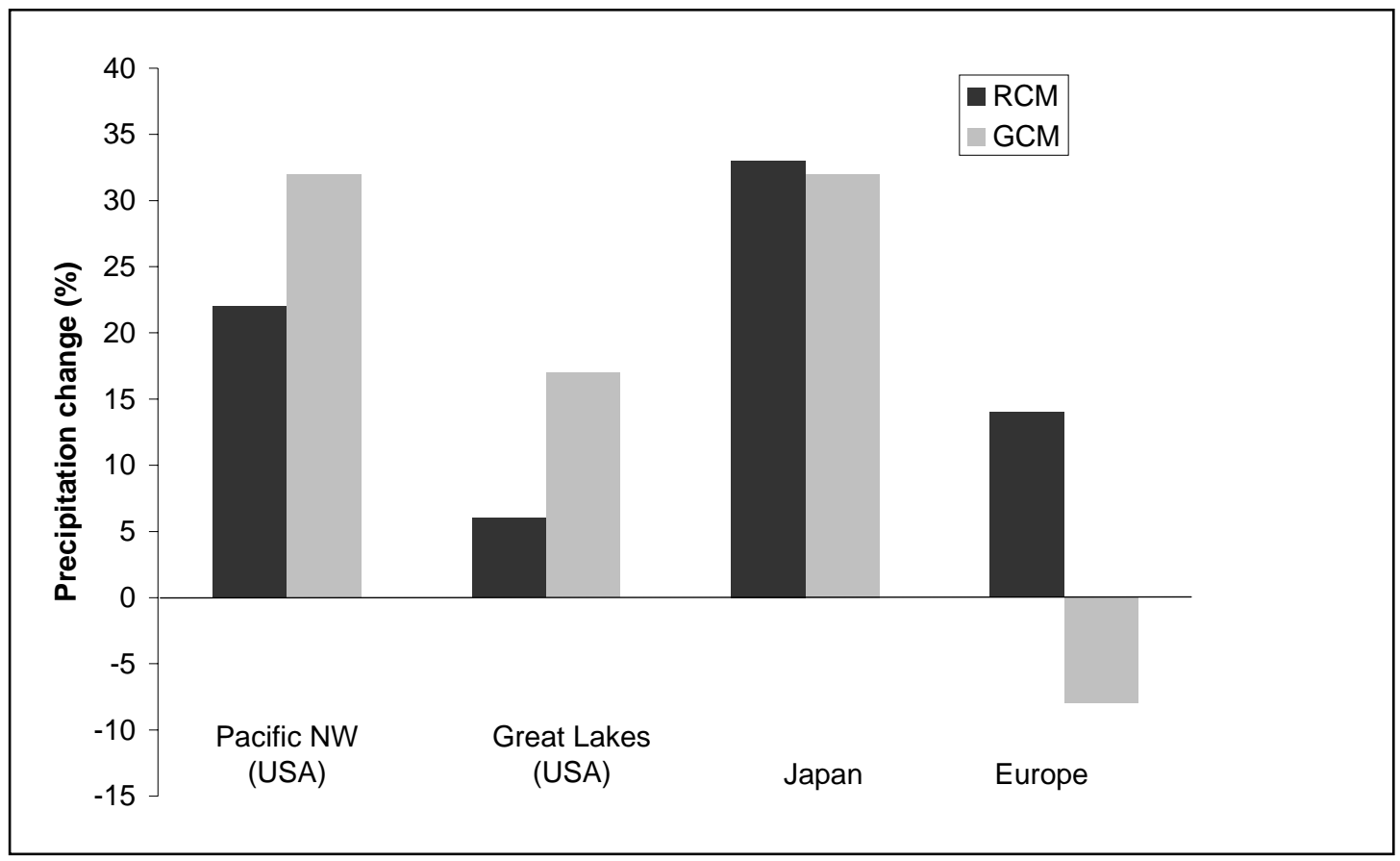


Figure 3

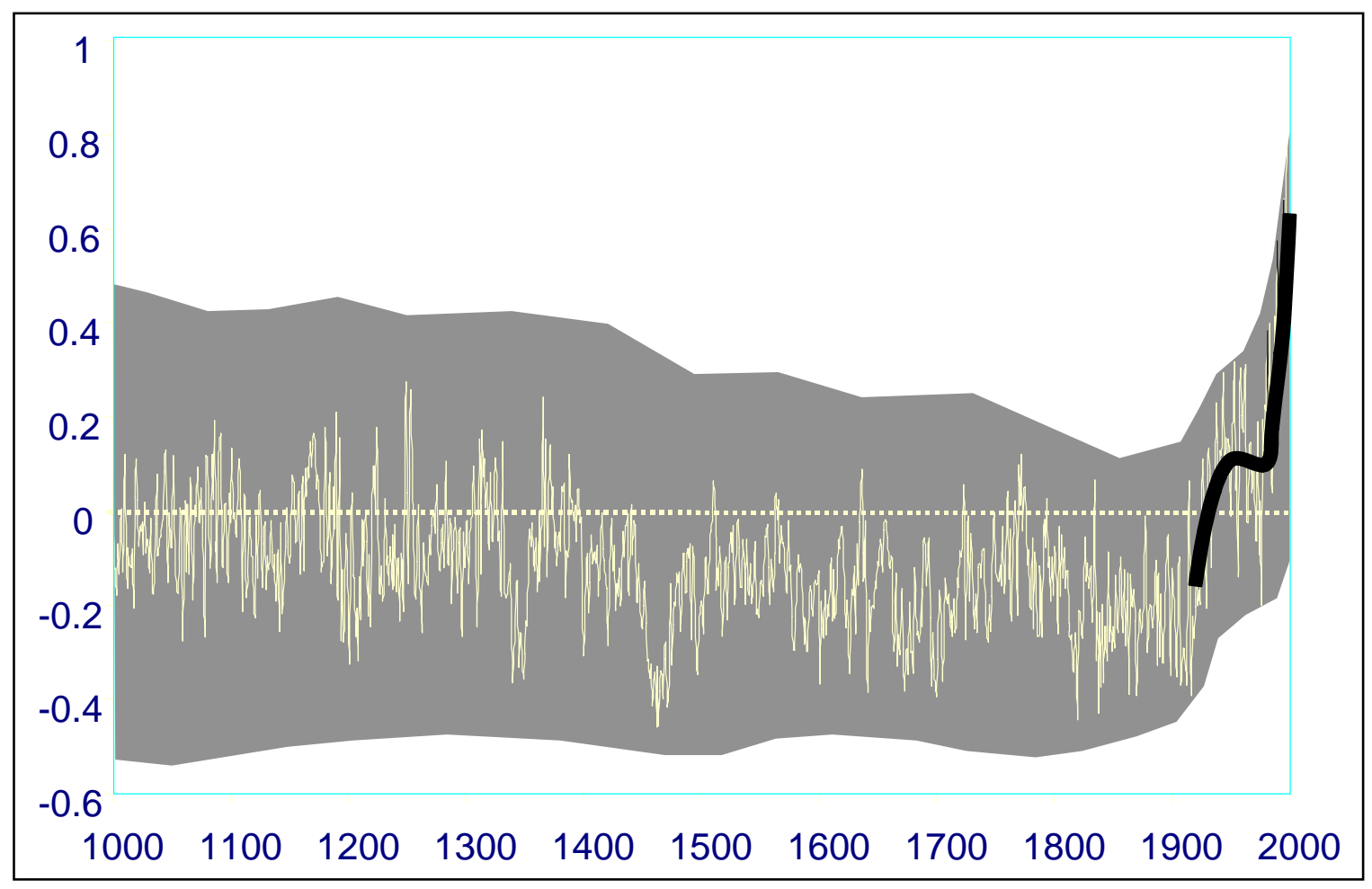


Figure 4

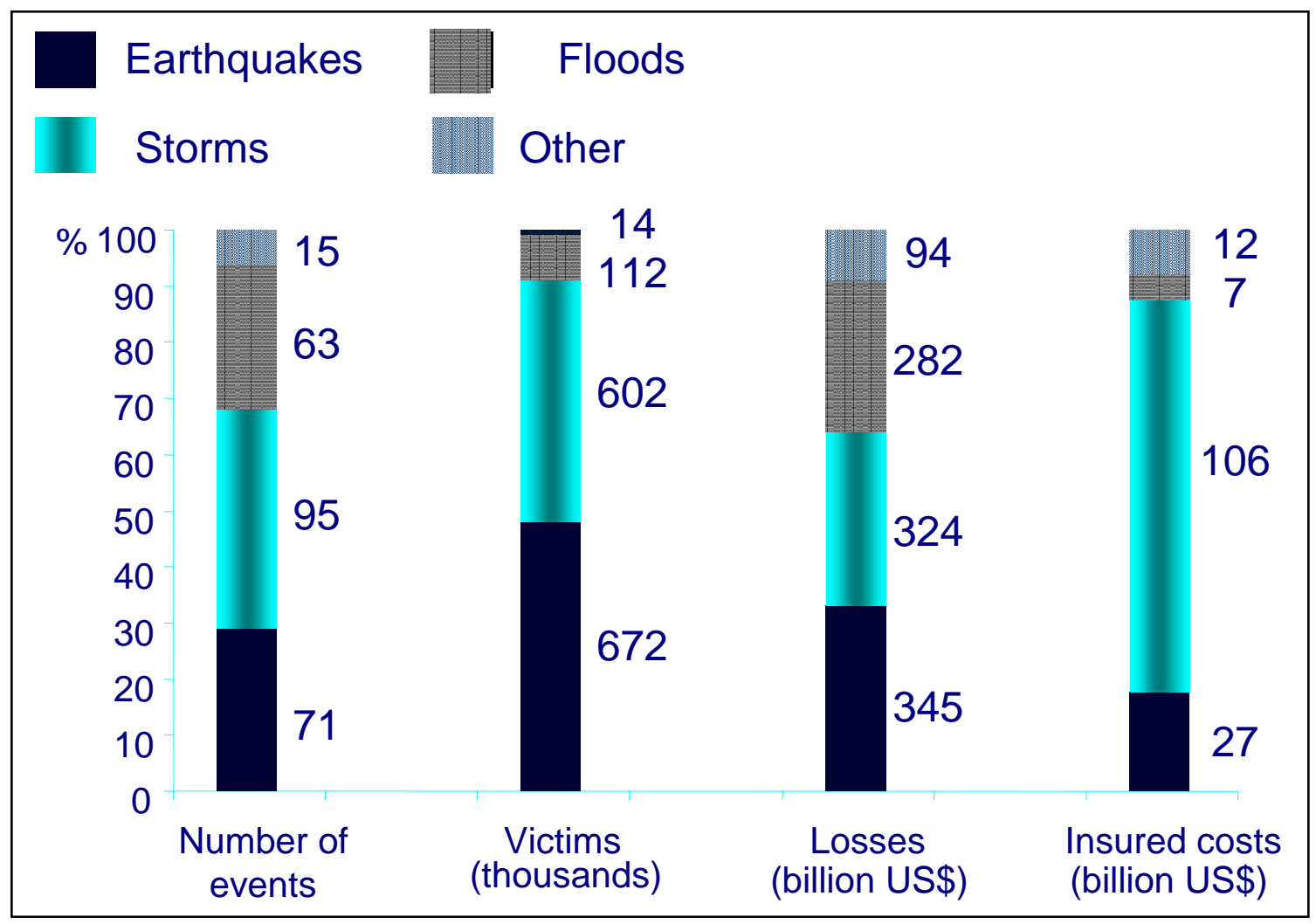


Figure 5

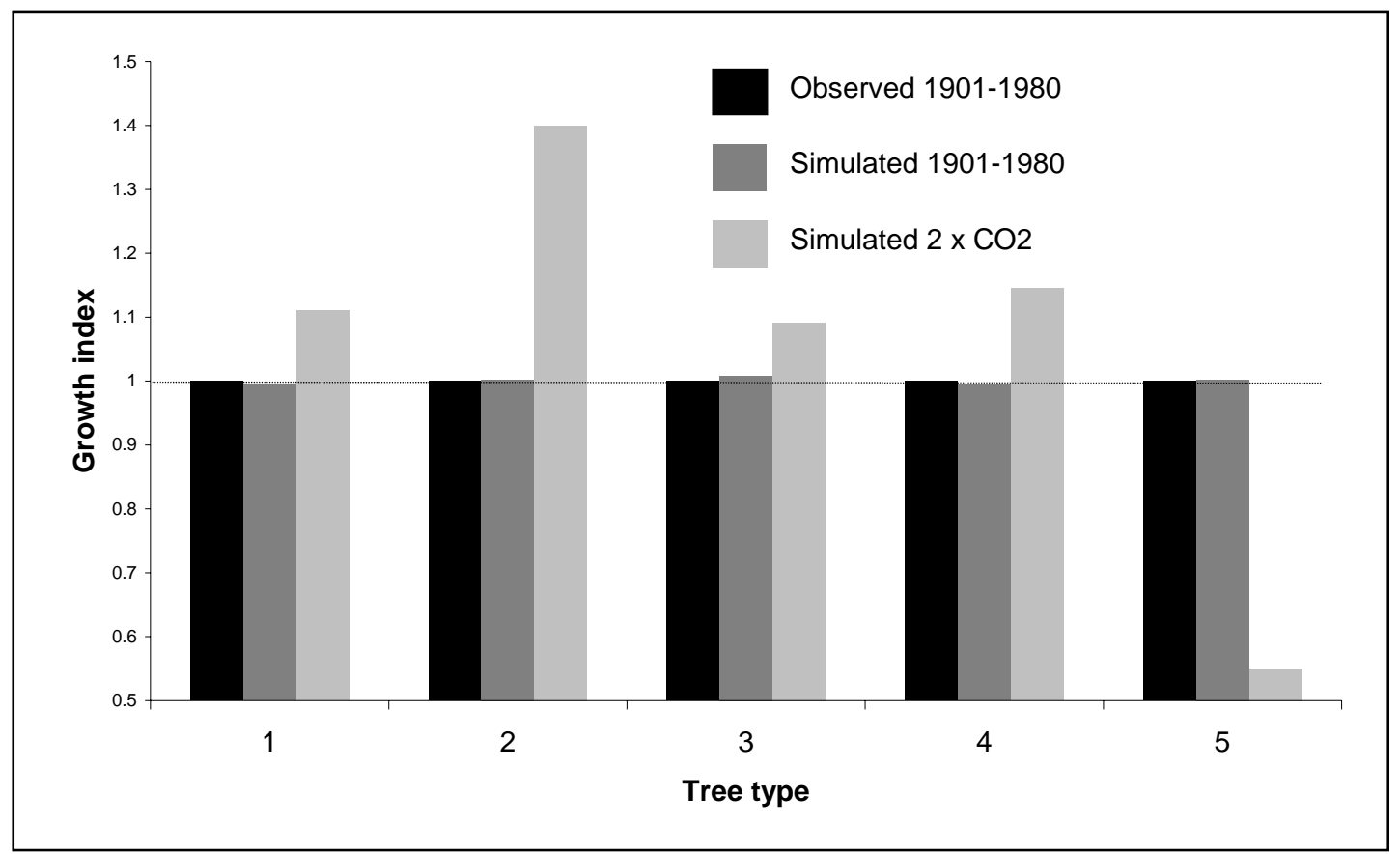

